\title{
Go Figure: A Path through Fictionalism
}

for Midwest Studies in Philosophy

Stephen Yablo

\section{Introduction}

There is the following predicament. One, we find ourselves uttering sentences that seem on the face of it to be committed to so-and-so's - sentences that could not be true unless so-and-so's existed. But, two, we do not believe that so-and-so's exist. ${ }^{1}$

What is someone caught up in The Predicament (as let's call it) supposed to do? The official standard menu of options was given by Quine in Word and Object. Our choices are three:

(1) show how the commitment can be paraphrased away - thus Quine himself on chances.

(2) stop uttering the problematic sentences - thus Quine on glints.

(3) give up one's resistance to the commitment -- thus Quine on sets.

Those who reject these options are subjected by Quine to some pretty withering criticism: "I deplore the philosophical double talk, which would repudiate an ontology while simultaneously enjoying its benefits" (242).

\section{Fourth Way}

Quine's menu and the associated moralizing have been terrifically influential. But they have occasioned a fair amount of resentment as well. How do we know the menu is complete? Might there perhaps be some other way of sticking with sentences whose commitments one does not share? Quine of all people should hope so, because he sticks with overcommittal sentences himself: 
I would [not] undertake to limit my use of the words 'attribute' and 'relation' to contexts that are excused by the possibility of ...paraphrase...consider how I have persisted in my vernacular use of 'meaning,' 'idea,' and the like, long after casting doubt on their supposed objects. True, the use of a term can sometimes be reconciled with rejection of its objects; but I go on using the terms without even sketching any such reconciliation. ${ }^{2}$

His excuse is that he does not go in for this sort of talk when speaking in "full scientific seriousness," "limning the true and structure of reality." But, how can it excuse an activity to say that one does not go in for it all the time? Quine does speak this way most of the time. And so we are entitled to ask: how do you get away with speaking in sentences committed to so-and-so's, where the commitment is not paraphrasable away?

Quine does not say a whole lot about this, and the things he does say do not always fit together. He has on the one hand his doctrine of "the double standard." Talk about attributes and meanings is excused by its limited ambitions.

What is involved here is simply a grading of austerity. I can object to using a certain dubious term at crucial points in a theory....but I can still use and condone the term in more causal or heuristic connections, where less profundity of theoretical explanation is professed. ${ }^{3}$

If the question is how Quine escapes commitment, the answer is that he does not escape it. He is in everyday contexts overcommitted; that's all right, because he never claimed in these contexts to be limning ultimate structure. This is the "apologist" strand in Quine.

But there has got to be more to the story than that. Statements that do not "limn ultimate structure" are false. And Quine does not think he found us false; he thinks he found us muddled. Ordinary speech is unclear. Our commitments cannot be read off of what we say. Canonical notation is introduced to bring these two back into line. A speaker's commitments in uttering non-canonical sentences are those of the canonical sentences she is content to put in their place. This is the "hermeneutic" strand in Quine, which seems clearly dominant.

Apologetic Quine thinks talk of glints is false, albeit excusably so. Hermeneutic Quine thinks it may not be false; so far though we have no explanation of how that could be. If I say "there is an X in the closet" when in reality there are no X's, haven't I 
misstated the facts? Maybe, but on the other hand maybe not. It depends on the spirit in which the sentence is put forward.

One way in which a man may fail to share the ontological commitments of his discourse is ... by taking an attitude of frivolity. The parent who tells the Cinderella story is no more committed to admitting a fairy godmother and a pumpkin coach into his own ontology than to admitting the story as true. ${ }^{4}$

Is it possible this is meant to apply more broadly, to statements that are not so obviously feigned?

Once again we get only hints. The language of belief attribution is for Quine an "essentially dramatic idiom." ${ }^{5}$ He says that the subjunctive conditional depends on "a dramatic projection," in that we are called on to "feign belief in the antecedent." ${ }^{6} \mathrm{He}$ speaks of the "deliberate myths"7 of the infinitesimal and the frictionless plane. Quine's view about these cases is resembles his view of fairy tales. He thinks that we can protect ourselves from ontological scrutiny by keeping the element of drama well in mind, and holding our tongues when the mood turns scientific. It appears then that Quine recognizes a fourth way of dealing with The Predicament. Someone whose sentences are committed to so-and-so's need not share in the commitment if

(4) the sentences are advanced in a fictional or make-believe spirit.

To have a name for this fourth option, let us call it fictionalism. There are a number of versions of fictionalism, according to the various accounts one might give of "advancing in a fictional spirit."

\section{Instrumentalist Fictionalism}

The fictionalist holds that we "make as if" we are asserting that $\mathrm{S}$ and/or believing that $\mathrm{S}$ and/or receiving the news that $\mathrm{S}$. Our reason for making as if we are doing these things (assuming we have a reason -- more on this below) is that it serves some larger purpose. Making as if S enables us simplifies our theory, or shortens proofs.

Someone who stops here - someone with no story to tell about what we are "really" doing in making as if S, and why that would be a sensible thing to do - I will call an instrumentalist fictionalist, or simply an instrumentalist. 
I see three main problems for instrumentalism. The first is phenomenological. When I say that "there is a world in which donkeys fly" or "the number of apostles is twelve" or " $2+3=5$," these utterances seem to mark genuine beliefs of mine, beliefs that I am trying to express and, if possible, communicate to others. If I am not sincerely asserting that the number of apostles is identical to the number twelve (I do not believe in numbers), I do seem to be sincerely asserting something. What is it? The instrumentalist doesn't say. Call this the problem of real content.

A second and related problem is that my utterances would seem to be characterizable as correct or incorrect. It is correct to say that $2+3=5$, incorrect to say that that $2+3=6$. The problems are connected in that, intuitively anyway, my utterance is correct iff its real content is true. By ignoring the real content side of the equation, the instrumentalist would seem to leave herself with no good way of distinguishing correct utterances from incorrect. Call this the problem of correctness.

The third problem is pragmatism. How is the instrumentalist going to fight off the Quine/Putnam objection that says: It quacks like a duck, so it is a duck. You say you do not really believe these sentences. But that certainly is not the way you act. You put the sentences forward, you get mad when people deny them, you engage in evidencegathering and proof-checking and all the rest. At the very least you owe us an account of how all this falls short of belief.

The account one would like to give is as follows. It is true that I carry on like a believer. But then, I am a believer. I believe the real contents of the sentences you hear me uttering. If people "deny" that the number of apostles is twelve, they are speaking not to the existence of numbers but to how many apostles there are. Naturally then I get mad! They are denying something that I think is really the case, viz. that there are twelve apostles.

An example of an instrumentalist fictionalist is Hartry Field in Science Without Numbers. Field has us quasi-asserting various things about mathematical objects because to do so shortens our proofs of claims about regular concrete objects. He does not as far as I know say that to quasi-assert $\mathrm{S}$ is to really assert something else $\mathrm{S}^{*}$.

An example of a non-instrumentalist fictionalist is Bas van Fraassen in The

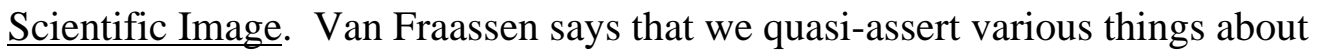


unobservables because this improves our ability to organize and derive results about observables. If that were the whole story, then van Fraassen would be an instrumentalist. But he says more: "When a scientist advances a new theory, the realist sees him as asserting the (truth of the) postulates. But the anti-realist sees him as displaying this theory, holding it up to view, as it were, and claiming certain virtues for it" (van Fraassen 1980, 57). One quasi-asserts the theory, but really asserts that it has certain virtues, such as empirical adequacy.

\section{Meta-Fictionalism}

Fictionalists usually have a story tell about how correct statements differ from incorrect ones. Van Fraassen thinks a statement is correct iff it is part of a theory with such and such virtues, among them empirical adequacy. Field thinks that a mathematical statement is correct iff it follows from standard mathematics. Schematically, we can say that $\mathrm{S}$ is correct iff $\mathrm{C}(\mathrm{S})$, where $\mathrm{C}$ is the condition the fictionalist puts forward as making for correctness. The difference between van Fraassen and (early) Field is that van Fraassen sees a quasi-assertion that $\mathrm{S}$ as at the same time a genuine assertion that $\mathrm{C}(\mathrm{S})$. (Field changes his view about this in the Introduction to Realism, Math, and Modality. Quasi-asserting that $2+3=5$ is, or can be, really asserting that according to standard math, $2+3=5$.)

So now we have a second sort of fictionalism, favored by van Fraassen and (later) Field. It says that in making as if to assert that $S$, one is really asserting that $\mathrm{S}$ is the right kind of thing to make as if to assert: the quasi-assertion game one is involved in endorses the quasi-assertion that $\mathrm{S}$. A natural label would be meta-fictionalism, for the real content concerns a sentence and its property of being a good or approved thing to say.

One problem with meta-fictionalism is modal in character. It ordinarily strikes us that $2+3$ is necessarily 5 ; it could not have been otherwise. But it could (perhaps) have been otherwise that $2+3=5$ according to standard math. For standard math could (perhaps) have been different. Certainly it is not a priori that standard math turned out the way it did. It is not a priori then that according to standard math, there are 
everywhere continuous functions that are nowhere differentiable. That there are functions like that is the kind of thing mathematicians take themselves to know a priori.

Second, there are problems of concern, of what we care about. It is a matter of concern that the number of starving people is large and rising. People do not seem to care in the same way about the content of standard math. If the meta-fictionalist is correct, though, quasi-asserting that the number of starving people is very large is really asserting that the number is large according to standard math. And it does not seem plausible that what we regret or deplore are or are concerned about here is that the number is large according to standard math. Because that would be to deplore inter alia part of the content of standard math.

Third is a phenomenological worry. When we say that the number of starving people is very large, we do not feel ourselves to be talking (even a bit!) about the content of a mathematical story. Our subject matter is people and our thought is that a lot are starving. "The number of apostles is twelve" is no more about a story than "snow is white" concerns the rules of English.

\section{Object Fictionalism}

I am certainly relying on the rules of English, when I utter the words "snow is white." It is those rules that make my utterance a way of saying that snow is white. It is just that relying on rules is one thing; talking about those rules is another. Likewise, when the words "the number of apostles is twelve" come out of my mouth, I am relying on the number-fiction. It is thanks in part to that fiction that my utterance is a way of saying that there are twelve apostles. Again, though, relying on a fiction is one thing; talking about it is another. The fiction (like the rules of English) functions as medium and not message.

Now, the rules of English make their contribution roughly like so. The rules tell us which sentences are true under which worldly conditions. If $\mathrm{K}$ is a condition sufficient by $\mathrm{R}^{\prime} \mathrm{s}$ lights for the truth of $\mathrm{S}$, we write $\mathrm{R}^{\mathrm{K}} \geq \mathrm{S}$. If $\mathrm{K}$ is necessary by $\mathrm{R}$ 's lights for the truth of $\mathrm{S}$, we write $\mathrm{R}^{\mathrm{K}} \leq \mathrm{S}$. $\mathrm{R}^{\mathrm{K}}=\mathrm{S}$ then means that $\mathrm{K}$ is what is needed for $\mathrm{S}$ to come out true, where truth is judged according to $\mathrm{R}$. The condition that $\mathrm{R}$ sets for the truth of $\mathrm{S}$ is the (literal) content of S. So 
(A) litcontent $(\mathrm{S})=\left[\right.$ the $\mathrm{K}$ such that $\left.\mathrm{R}^{\mathrm{K}}=\mathrm{S}\right]$

There is terminology for this in mathematics. The exponent $\underline{\mathrm{k}}$ to which you have to raise $\underline{r}$ to obtain $\underline{s}$ is $\log _{\underline{r}}(\underline{s})=$ the logarithm of $\underline{s}$ to the base $\underline{r}$. So another way to put it is

(B) litcontent $(\mathrm{S})=\log _{\mathrm{R}}(\mathrm{S})$

Note the contribution of $\mathrm{R}$. The rules associate a particular content with $\mathrm{S}$, but they do not figure in that content. (B) does not implicate $\mathrm{R}$ in the content any more than $2=\log _{3} 9$ implicates 3 in 2.

The role just envisaged for $\mathrm{R}$ is the role we want fiction $\mathrm{F}$ to play as well. The real content of $S$ is not that $S$ is fictional, that is, true according to $F$. The real content is the circumstance $\mathrm{K}$ that makes $\mathrm{S}$ fictional, the fiction taken for granted. Letting $\mathrm{F}^{\mathrm{K}}=\mathrm{S}$ mean that $\mathrm{K}$ is that circumstances, we want

(A') realcontent $(\mathrm{S})=\left[\right.$ the $\mathrm{K}$ such that $\left.\mathrm{F}^{\mathrm{K}}=\mathrm{S}\right]$.

As before, the exponent to which $\mathrm{F}$ needs to be raised to obtain $\mathrm{S}$ can be written as a logarithm:

(B') realcontent $(S)=\log _{\mathrm{F}}(\mathrm{S})$.

This is the defining formula of object fictionalism. S as we use it really means that $\log _{\mathrm{F}}(\mathrm{S})$, where $\log _{\mathrm{F}}(\mathrm{S})$ is not the fact that makes $\mathrm{S}$ true, but the fact that makes it fictional.

Which facts these are depends on the governing fiction, of course. The governing fiction of applied arithmetic says that whenever there are some E's, there is an entity their number that measures them cardinality-wise; if there are five E's, this further entity is 5, if there are a million, it is $1,000,000$. The governing fiction of possible worlds theory says that whenever something is possible there is a world where it happens. The governing fiction of property theory says that whenever there are some Q's and nothing else is Q, there is a property Q-ness exemplified by all and only those things. ${ }^{8}$ Assuming fictions of this general sort, we have

$\log _{\mathrm{F}}($ the number of E's $=\underline{\mathrm{n}})=$ there are $\mathrm{n} E$ 's.

$\log _{\mathrm{F}}($ there is a world such that $\mathrm{H})=$ possibly $\mathrm{H}$.

$\log _{\mathrm{F}}(\underline{\mathrm{x}}$ has $\mathrm{Q}-\mathrm{ness})=\underline{\mathrm{x}}$ is $\mathrm{Q}$.

(B') now tells us that

realcontent $($ the number of G's $=\underline{\mathrm{n}})=$ there are $\mathrm{n} \mathrm{G}^{\prime} \mathrm{s}$.

realcontent $($ there is a world such that $\mathrm{H})=$ possibly $\mathrm{H}$. 
realcontent $(\underline{\mathrm{x}}$ has $\mathrm{Q}-\mathrm{ness})=\underline{\mathrm{x} \text { is } \mathrm{Q}}$.

If it is the real content that one really asserts, then

quasi-asserting "the number of G's $=\underline{\mathrm{n}}$ " is really asserting that there are $\mathrm{n}$ G's.

quasi-asserting "there is an $\mathrm{H}$-world " is really asserting that possibly $\mathrm{H}$.

quasi-asserting "x has Q-ness" is really asserting that $\underline{\mathrm{x}}$ is $\mathrm{Q}$.

In all these cases we rely on the fact that what is true in a story does or can depend on what is true in reality. One gives voice to the real truth by making as if to assert the fictional truth that it enables.

How does this help? Start with the problems of phenomenology and concern. When we say that the number of starving people is very large, the real content is that there are very many starving people. When we say that the number is rising, the real content is that there were so many starving people yesterday, more today, more tomorrow, and so on. These are facts not about the story but about people. And they are facts it makes sense to feel concern about.

Object fictionalism helps too with the modal problem. The real content of " $2+3=5$ " is the worldly fact that makes it true in the number-story. If the story takes the expected sort of shape, what makes it true in the story that $2+3=5$ is that if there are two F's, and three G's, then barring overlap there are five (F-or-G)'s. When this is written as a sentence of first-order logic (numerical quantifiers are defined inductively in the manner of Frege), it is seen to be a logical truth. ${ }^{9}$ No wonder $" 2+3=5$ " strikes us as necessary and a priori; at the level of real content, it is.

\section{The Bomb}

Object fictionalism is on the right track. But as stated it is subject to a knock-down objection (the Bomb). It is an objection that arose first in connection with Gideon Rosen's "modal fictionalism" and that was generalized to other sorts of fictionalism by Daniel Nolan and John Hawthorne. ${ }^{10}$

$\mathrm{S}$ is quasi-assertible iff it is true according to the story; and it is quasi-assertible iff its real content obtains. Consider what this means in the context of applied arithmetic. We have on the one hand that

(a) $" \#\left(K^{\prime} s\right)=n "$ is quasi-assertible iff according to the number-story, $\#\left(K^{\prime} s\right)=\underline{n}$.

We have on the other hand that 
(b) $" \#\left(K^{\prime} s\right)=n "$ is quasi-assertible iff there really are $\underline{n} K^{\prime} s$.

Now, certainly the following is true:

(c) according to the number-story, \#(even primes) $=1$.

From (a) and (c) it follows that

(d) "\#(even primes) $=1 "$ is quasi-assertible.

From (b) and (d) it follows that

(e) there really is an even prime number..

But of course (e) is not something your typical fictionalist would want to accept; it certainly is not something she wants to be forced into accepting. The whole motivation after all was to find a construal of number-talk that did not find you to be actually committed to the things! So it really is a disaster if from the fictionalist's own proposal it follows that numbers do exist -- if, as Rosen puts it, the fictionalist winds up a platonist malgre lui.

Suppose we turn the argument around, working backwards from the fictionalist's desired result. She wants to maintain (or to preserve the right to maintain) that (e') there really are no numbers. From this it follows via (b) that $\left(\mathrm{d}^{\prime}\right)$ "\#(numbers) $=0$ " is quasi-assertible.

This and (a) give us

$\left(c^{\prime}\right)$ according to the number-story, $\#($ numbers $)=0$.

And that is false. According to the number-story, the number of numbers is very much larger than 0 . You get the same sort of problem with other applications of the object-fictionalist strategy. Property-fictionalists, for instance, want to be able to say that (e") there are no properties. But then they are committed via (a) and (b) to (c") according to the property-story, being a property has no instances. It is not true, though, that according to the property-story, being a property has no instances. According to the property-story, being a property has lots of instances, namely all the properties.

The results we are getting seem in fact to be worse than false. Take "the number of numbers is 0." That has no chance of being true, because it is self-refuting. If the number of numbers is 0 , then there is one number at least, namely 0 , and so the number of numbers is not 0 after all. Likewise the statement that is said to be true according to the property-story. How could being a property have no instances, when it is itself an instance? It seems that either the fictionalist is a platonist, or the story becomes incoherent. 


\section{How I Learned to Love the Bomb}

"The number of numbers is 0" seems at first obviously false. But there are settings where statements of the same basic form strike us as not false but true. Example: Sometimes we say that a person is "full of it". (I will understand this as in a familiar way elliptical for something we would rather not come out with.) Holocaust deniers are full of it; Pat Buchanan is full of it. "Full of it" is, I assume, never meant, or taken, literally. But we can imagine a context where this happens. Imagine a speaker Ned so naïve as to think that when Buchanan is described as full of it, this is to be understood as a surprising but well-supported claim about the contents of Buchanan's body. A joker Jerry has been feeding this information to Ned, and Ned has come to believe that Jerry is right. Jerry has told Ned that when he (Jerry) describes Buchanan as full of it, he is to be taken literally. What can say to Ned to set him straight?

One thing we might say is that Buchanan is not really or literally full of it. Ned objects that his friend Jerry has told him otherwise. Why, if Buchanan is not really full of it, is this so often said? It is not often said, we explain; "full of it" is a figure of speech. Ned replies that this begs the question. It seems a figure of speech to us, because we think a literal interpretation would be uncharitable, because we do not appreciate the true facts about Buchanan as expounded by Jerry. At this point we are likely to just throw up our hands and say (?\#\%) anyone who says people are full of it is full of it! Now, try if you can to forget the preamble and look at the last sentence again.. Taken out of context, it looks self-defeating in the manner of "the number of numbers is $0 . "$ It looks like you are calling a certain kind of person a liar, a kind that includes you yourself. But, of course, there is another way of hearing (?\#\%) so that it makes perfect sense. If we take the first occurrence of "full of it" literally, and the second occurrence figuratively, it says that people who say that people are literally full of it are liars. And that is true.

Suppose that Ned is naïve not just about "full of it" but also about "the number of G's is so and so." He has been told by Jerry that the point and purpose of saying that the number of Martian moons is 2 is to state an identity between one number, the one that numbers the Martian moons, and another, the number 2 . If we are nominalistically inclined fictionalists, we will tell Ned that another interpretation is needed, because there aren't any numbers. He replies, but Jerry says there are; Jerry says that the number of numbers is huge (aleph-nought). Our counter-reply is that far from being aleph-nought, the number of numbers is 0 . 


\section{Reflexive Fictionalism}

Now we have seen how to say "the number of numbers is 0 " and have it come out not self-defeating but, by the nominalist's lights, true. What we haven't seen is what exactly is going on in these cases. What is wrong with the object fictionalist's idea that we introduce X's (numbers, say) to help us to talk about Y's (concreta)?

There are actually two roles X's can play. Sometimes they function as representational aids. This is how butterflies function in "I had butterflies in my stomach," and numbers functions in "the number of Martian moons is 2." Other times they function as thingsrepresented. This is how butterflies function in "the butterflies were splattered all over the windscreen," and how numbers function in "there are no numbers, that's just a way of talking."

Object fictionalism as written can't handle this distinction. Object fictionalism never contemplates for a moment that X's will function as things-represented. No surprise then that mechanically applying its rules in cases where they do so function leads to unwanted results.

Reflexive fictionalism is object-fictionalism modified to take account of all this. X's can be representational aids, or not (two possibilities). X's can be things represented, or not (once again, two possibilities). Multiplying two by two, this gives us four types of statement -- three, if we leave aside the case in which X's function in neither way ("the cat is on the mat"). Each of the three blocks the self-defeat argument (a)-(e) in a different way.

(1) There are sentences in which X's function just as representational aids ("the number of Martian moons is 2"). Call this applied X-talk. If we are engaged in applied X-talk, then $\mathrm{K}$ is a predicate of "regular" things (concreta), not a predicate of X's (numbers). The inference from (b) to (c) has $\mathrm{K}$ a predicate of numbers. So if applied X-talk is our game, the argument does not get beyond (b).

(2) There are sentences in which X's function just as things represented; for example, "there are numbers" (spoken by the platonist) and "there are no numbers" (spoken by the nominalist) and "there is an even prime" as it occurs in the self-defeat argument. Call this explicit X-talk. If I am speaking explicitly, then I am not using numbers as representational aids. But then (a) and (b) are off limits, for they are principles of quasi-assertion, and there is quasi-assertion only when numbers are playing a representational role. 
(3) There are sentences in which X's function in both ways, for instance, "the number of even prime numbers is $0 "$ as spoken by a nominalist. 0 is functioning here as a representational aid, while the primes are things-represented. Call this self-applied X-talk. If it is self-applied Xtalk we are going in for, then (a) is applicable in principle but will be regarded by the nominalist as false. (a) says that quasi-assertibility is truth according to the number fiction. But although it is true in the fiction that the number of even primes is 1 , the nominalist (as just noted) quasiasserts that the number of even primes is 0 .

I said that object fictionalism mishandles the distinction between representational aid and thing-represented. It is not blind to the distinction, for it puts numbers in the first category and concreta in the second. The point it misses is that X's can travel back and forth between the two categories. Not only can they change sides between games; they can do it within a game, indeed within a single sentential move.

Reflexive fictionalism tries to take account of the fact that X-sentences are open to multiple interpretations, corresponding to the various ways of divvying up their $\mathrm{X}$-ish allusions between the sincere and the as-if. The obstacle to multiple contents is our all-purpose governing fiction F. So F will have to go. In its place we put make believe games G, where it is understood that different such games can be played with the same sentences, and will be as the occasion demands. Changes in the game we are playing with $\mathrm{S}$ make for changes in real content, according to the following rule: realcontent $(S)=\log _{G}(S)$, where $G$ is the operative game. (Applied X-talk becomes self-applied when acceptability in $\mathrm{G}$ falls under the control of facts about Xs.) The real content is the condition, whatever it is, to which $\mathrm{S}$ owes its acceptability in the game.

\section{Relative Reflexive Fictionalism}

Now I want to argue that reflexive fictionalism is not much use, and has to be treated as a station on the way to something better. Imagine that you are a nominalist taking reflexive fictionalism out for a spin. You are excited by the reports you have heard of using X's to talk about X's, and have been looking forward to the opportunity to try it yourself. What sort of description shall you attempt first? What about the numbers lends itself to numerical representation? Immediately your excitement begins to fade. You are not in a mood to attempt any description of the numbers, because in your view there are no such things. Or rather, 
you are not in a mood to attempt any description beyond "there aren't any." It is true that one can say that with numbers (as in the last section). But it is hard to see why anyone would bother. "There aren't any" sums the matter up nicely.

Perhaps then we should have made you a platonist taking reflexive fictionalism out for a spin. You do not deny the existence of numbers; a subtle transcendental argument persuades you that they are real. It is just that you don't think ordinary people are talking about these transcendentally motivated entities when they say in ordinary contexts that $2+3=5$. (They are talking about numbers as much or little as one is talking about Shirley's petard -- let's say she has one -- when describing her as hoist upon it.) There are some people, however, namely platonistic philosophers like yourself, who do talk about numbers, and in them reflexive fictionalism would seem to have found its constituency. Believers in numbers presumably want to say useful and informative things about them. And so they should be interested in technologies that help with this project; and the fiction of numbers is just such a technology. You should be excited then about what the fictionalist has to offer.

Or should you? You do indeed want to use numbers for representational purposes. But what possible advantage could as-if numbers have over real ones: the numbers that you as a platonist genuinely believe in? Nominalists (you will say) might benefit from the fiction of numbers, since they have no other access to the referential/quantificational maneuvers that numbers enable. But you as a platonist do not need the fiction to engage in these maneuvers. You have been quantifying over numbers all along, as you are entitled to do given your belief that they are there. It is interesting, perhaps, to realize that the fiction could step in if your genuine numbers proved to be an illusion; the same representational advantages would accrue. But even that should not impress you much. If numbers proved to be an illusion, then the descriptive challenges they seemed to present would have proved illusory too. "There aren't any" is not all that hard to say.

Who then is reflexive fictionalism really benefiting? No one, it seems. And so we need to make changes. There is one last distinction that needs to be folded into the mix.

Suppose that you as a nominalist say "there are not many even prime numbers." There are two ways he might want to be understood. Perhaps you are trying to portray the numbers as they are. You think there aren't any numbers, and conclude from this that there aren't any, or hence many, even prime numbers. In this case we will say you are speaking in a disengaged manner. 
The other possibility is that you are trying to portray the numbers as they are supposed to be imagined by players of the relevant game. You say "there are not many even primes" because you know that the numbers are to be thought of as including just one even prime. In this case we will say you are speaking in an engaged manner.

If you are a disengaged nominalist, then you and the platonist have not much to talk about. She insists there are lots of prime numbers, you insist there are none, and the discussion breaks down. When an engaged nominalist meets a platonist, things go better. The platonist says, "do you think that the number of even primes is 1?" And you reply, not, "what do you mean, there are no numbers," but, "yes, and here is the proof."

Both of these conversations have (erstwhile) representational aids taking on the role of things-represented. Both, then, should be grist for the reflexive fictionalist mill. Only one of the conversations, though, is allowed by that doctrine. Provision has been made for talking about the numbers as they are, but not for talking about them as they are to be imagined. The disengaged nominalist gets what he wants, but the engaged one is stiffed.

Any real nominalist will want to be both of these characters. He will want to be disengaged when speaking to philosophers ("there being no numbers at all, the number of even primes is $0 "$ ), and engaged when doing mathematics ("4, 6, 8, . being composite, the number of even primes is 1"). This is a kind of relativism, and so reflexive fictionalism modified to allow for it will be called relative reflexive fictionalism. No changes are needed on the disengaged side, but the engaged nominalist (the one who rejects numbers but not number theory) needs our help.

The solution is to allow a new type of game. $\mathrm{G}$ is $\underline{\text { basic }}$ if acceptability in $\mathrm{G}$ is a function of how things really are; these are the games we have been talking about so far. $\mathrm{G}^{*}$ is parasitic if acceptability in $\mathrm{G}^{*}$ depends on how things are imagined to be when playing some other game (as it might be, G). The engaged nominalist is speaking parasitically. He is playing a $\mathrm{G}^{*}$ in which numbers are assigned to the entities imagined to exist when playing $\mathrm{G}=$ the "applied" game in which numbers are assigned to entities that are really there. The numbers as they are imagined to be in $\mathrm{G}$ include just one that is even and prime; $\mathrm{G}^{*}$ assigns 1 to the so-and-so's iff there is only a single so-and-so among the numbers as they are imagined to be in G; hence G* assigns 1 to the even primes. (The appearance of stratification here is actually somewhat misleading, for parasitic games tend to swallow their hosts; instead of two games, one parasitic 
on the other, we wind up with a single game parasitic on itself. Details to be given elsewhere, I hope.) ${ }^{11}$

\section{Communication}

Nominalists and platonists do not disagree about the number of even primes. Of course, the nominalist is talking about numbers as they are postulated to be in the game. But the platonist has, or should have, no real objection to this. The numbers she postulates are supposed to be really there. But apart from that one detail, they are indistinguishable from the numbers as the arithmetic-doing nominalist imagines them.

Saying this goes a little way towards addressing an under-discussed problem in the philosophy of mathematics. How is it that mathematicians can happily communicate despite having different views of the nature, and even the existence, of mathematical objects? How can the ontological questions that philosophers sweat over be so irrelevant to actual practice?

One answer goes back to Carnap. Talk about numbers is internal to the numberframework, and responsible only to that framework's rules of assertion. "True" is a label we apply to the sentences the rules let us utter, and "agreement" is the label we use when the same sentence is uttered by more than one person. Not many have found this answer satisfying. We ask how mathematicians can agree despite their ontological differences, and we are told in effect to ignore those differences. To ignore them is to ignore what the discussants take themselves to be saying, and to that extent what they are saying. An account of agreement that ignores that is bound to be superficial. It is good that mathematicians do not come to blows over what sentences to accept. But we cannot speak of agreement until we know what the sentences mean in their mouths.

Fictionalism tries to speak to this question. It is agreed how the numbers are to be conceived; they are to be conceived as an omega-sequence generated from 0 by successive application of +1 . And it is agreed that entities answering to that conception would have to have such and such features, such as including infinitely many primes.. True, the platonist thinks that there really are some things with these features; and perhaps also that we are to conceive the numbers with these features because they are the features they really have. True, the nominalist tends to doubt these claims. But that makes little difference in practice. Each hears the other as 
talking about numbers as they are taken to be. They can agree that number-talk is answerable to that, while agreeing to disagree on whether the taking is veridical.

Everyone should now be happy, it seems. The platonist (for whom the taking is veridical) gets real (platonistic) truth. And the nominalist gets real agreement along the lines just sketched. If there is a problem here, it is that the first "real" does not work the same way as the second. Both "real"'s look back to real content, but they draw on different aspects of the notion, which we have until recently been running together.

Question: What makes real content real? Answer \#1: It concerns real things, for instance, moons as opposed to numbers. Call this the objectual reality of real content. Answer \#2: It is really asserted. Call this the assertional reality of real content.

One way of putting the moral of the last section is that objectual and assertional reality can come apart. Suppose that I as a nominalist declare the number of primes to be infinite. Assertional reality is not lacking. There is something that I am really saying, as opposed to just pretending to say. But there is no real content in the objectual sense. I am talking about the numbers as they are supposed to be imagined, not the numbers as they are. This has consequences for the communication problem.

The platonist agrees with the nominalist about the numbers as they are taken to be. But that is not, for her, the content of interest. When she says "there are infinitely many primes," she means to be claiming that some bona fide numerical entities are infinite in number. The nominalist's real content is only assertionally real, but hers, she believes, is real in both of our senses. She may then balk at the suggestion that she and the nominalist agree about the number of primes. The nominalist says: you believe what I mean by "there are infinitely many primes," so we agree. The platonist says: you do not believe what I mean by "there are infinitely many primes," so we do not agree. (I will not try to address this problem here, except to say that I doubt that the platonist is advancing an objectually real content, as claimed. One does not assert the reality of numbers except when doing philosophy, and we were talking about agreement in mathematics.)

\section{Figuralism}


Revolutionary nominalists want us to stop talking about so-and-so's; hermeneutic nominalists maintain that we never started (Burgess and Rosen 1997). A nominalism based on the methods sketched here would, one imagines, be revolutionary. But then it seems fair to object that the view is extremely complex. A revolution with this many rules is unlikely to generate a whole lot of fervor.

Reply: Actually, the proposal is put forward in more of a hermeneutic spirit. "What, we are all relative reflexive fictionalists without realizing it?" No, but we are something closely related. We are people apt on occasion to speak figuratively. There is nothing in relative reflexive fictionalism not found already in figurative speech.

If, as is sometimes supposed, "linguistic usage [is] literalistic in its main body and metaphorical in its trimming...," then we are barking up the wrong tree. A device that special and unusual cannot support the explanatory burdens that hermeneuticism imposes. If, on the other hand, it is literal speech that is special -- if, as Quine says,

Cognitive discourse at its most dryly literal is largely a refinement.... It is an open space in the tropical jungle, created by clearing tropes away $(1978,188-9)$--

then figurative fictionalism might be just what the doctor ordered. Already we have seen how figures can help. It seemed at first quite mysterious how "the number of even primes is zero" could possibly be true -- and still more mysterious how it could also be true (as in mathematical contexts it seems to be) to say that the number of even is not zero. Then a metaphor was found with the same convoluted-looking structure. "Those calling people full of it are full of it" is true when the first "full of it" is taken literally, and false if it is taken another way.

"Full of it" is, if I may so put it, the tip of the iceberg. A lot of the phenomena that fictionalists are called on to explain are already present in figurative speech and handled effortlessly there. Some examples:

(A) "7 is less than $11 "$

$\approx$ "the back burner is kept at a lower temperature than the front" "pinpricks of conscience register less than pangs of conscience" "a molehill is smaller than a mountain"

(B) "11 is prime" 
$\approx$ "the back burner is where things are left to simmer" "the invisible hand operates all by itself, without encouragement or supervision" "emotions run high when the green-eyed monster visits"

(C) "prime numbers are mostly odd"

$\approx$ "stomach-butterflies do not sit still but flutter about" "apron-strings are short" "molehills are nothing to get excited about"

(D) "the number of F's is large iff there are many F's"

$\approx$ "your marital status changes iff you get married or..." "your identity is secret iff no one knows who you are" "your prospects improve iff it becomes likelier that you will succeed"

(E) "the F's outnumber the G's iff $\{x \mid F x\}$ is bigger than $\{x \mid G x\}$

$\approx$ "they are more audacious than you iff they have more gall" "those are more widely available than these iff their market penetration is greater" "they are better justified than you iff their reasons are better"

(F) "the \# of F's = the \# of G's iff there are as many F's as G's"

$\approx$ "our greatest regret $=$ yours iff we most regret that so-and-so and so do you" "our level of material well-being = yours iff we are equally well off" "my bottom line is the same as yours iff both of us are prepared to settle for such-and-such and neither is prepared to settle for anything less"

The similarities here run deep. All of the above statements seem necessarily true. It is no accident that if there are as many F's are as G's, then the F's and G's have the same number. It is no accident that if neither of us is prepared to settle for less than the other, then our bottom lines are the same.

Second, all of the statements employ a distinctive vocabulary - "number," "bottom line" -- which vocabulary can also be used to make contingent claims about concrete reality ("the number of sheep exceeds the number of goats," "negotiations have been difficult, because their bottom line keeps on changing"). 
Third, its suitability for making contingent claims about concrete reality is the vocabulary's reason for being. No one cares about stomach-butterflies as such; the question of interest is whether people have butterflies in their stomach. Just so, our interest in 11 has less to do with its relations to 7 than with whether, say, the eggs in a carton have 11 as their number, and what that means about the carton's relation to other cartons whose eggs have a different number.

Fourth, the vocabulary's utility for this purpose does not depend on conceiving of its referential-looking elements as truly standing for things. Those if any who take bottom lines and numbers dead seriously derive the exact same expressive benefit from them as those who find the notion laughable. And both of these groups derive the exact same expressive benefit as those who never gave the matter the slightest thought.

\section{Rationale}

At one time the rationale for fictionalism was obvious. We had, or thought we had, good philosophical arguments to show that X's did not exist, or could not be known about if they did. X's were obnoxious, so we had to find an interpretation of our talk that didn't leave us committed to them.

That form of argument is dead and gone, it seems to me. It requires very strong premises about the sort of entity that can be known about, or that can plausibly exist; and these premises can always be exposed to ridicule by proposing the numbers themselves as paradigm-case counterexamples. ${ }^{12}$

But there is another possible rationale for fictionalism. Just maybe, it gives the most plausible account of the practice. It is not that X's are intolerable, but that when we examine X-language in a calm and unprejudiced way, it turns out to have a whole lot in common with language that is fictional on its face. If one now asks, which elements of everyday speech are fictional on their face, the answer is the figurative elements.

I can illustrate with, you guessed it, the example of numbers. The decision between platonism (including here platonistic semantics) and fictionalism (the figuralist variety) turns on four related questions. 
+PLA What does platonism help us to explain? What phenomena are there that make more sense if platonism is true?

-PLA What explanatory puzzles does platonism generate? What becomes hard to make sense of if platonism is true?

+ FIG What does figuralism help us to explain? Are there phenomena that make more sense if figuralism is true?

-FIG What explanatory puzzles does figuralism generate? What is there in the figuralist picture that seems puzzling or inexplicable?

Arguments from obnoxiousness ignore the other three questions to focus on -PLA. One is left to suppose that platonism comes out so far ahead on the other questions that the figuralist needs a big win on -PLA to survive.

This is where old-style fictionalism makes its big mistake. It allows and even encourages the notion that the benefits are all on the side of platonism, and the only way to oppose platonism is to harp on the terrible costs. A better strategy is to say that the "benefits" are largely nonexistent, and the figuralist can explain more than you thought, on a less fanciful basis than you thought. I cannot argue these points in detail here, but some examples will give the flavor.

\section{What does platonism help us to explain?}

If there really are numbers, then there is an objective fact of the matter about which arithmetical statements are true. Take the numbers away, and all that is left is the human practice of developing and swapping around proofs, plausibility arguments, suggestive analogies, etc. And that practice, not to say it isn't highly disciplined, cannot provide as objective a basis for arithmetical truth as a bona fide number series would. The decision problem for arithmetic is of staggering complexity. There is nothing we can do to decide matters this complex. That is a task for the numbers themselves.

Response: Either our conception of the numbers is determinate or it is not. By 
"determinate," I mean that for any arithmetical claim S, one of the following is determinately correct: (i) any structure $\mathbf{N}$ answering to our conception would be such that $\mathbf{S}$, or (ii) any structure $\mathbf{N}$ answering to our conception be such that not-S. Our conception is indeterminate if there are arithmetical claims $\mathbf{S}$ such that an $\mathbf{N}$ answering to our conception might or might not be such that $\mathrm{S}$. Our conception leaves certain things open which, settled one way, make for an S-structure, and settled another way make for a structure such that not-S.

Suppose first that our conception of the numbers is determinate. Then the numbers are not needed for objectivity. Our conception draws a bright line between true and false, whether anything answers to it or not.

If our conception is not determinate, there is a question as to how we nevertheless manage to pick out the intended structure. (I assume that we do pick it out, up to isomorphism, since if not even the platonist ha objectivity problems.)

The answer has got to be that the world meets us half way; of the various technically eligible candidates, only one exists. "The numbers" are whatever out there best corresponds to our not fully determinate intentions.

This however makes it a (conceptually) contingent matter which arithmetical claims are correct. There will be arithmetical claims $S$ that are true in our mouths, but false in the mouths of our intrinsic duplicates -- false in the mouths of (conceptually) possible people just like us internally but who live in a universe with undetectably different numbers.

Arithmetical concepts are not supposed to be externalist in this way. It should not be that although I am right when I say that there are infinitely many primes differing by two, my doppelganger on Twin-Prime Earth is wrong when he says the same thing. If there are infinitely many twin primes, the reason should not be that such and such are the number-like entities that happen to exist.

So the number-hypothesis, conceived as objectivity-bolstering, is faced with a dilemma. If we are clear enough about what we mean by it, then the hypothesis is not needed for objectivity. And if we are not clear what we mean, then it is not going to help. It is not even going to be tolerable because arithmetical truth is going to blow with the ontological winds in a way that nobody wants. 
What does figuralism help us to explain?

InSUBSTANTIALITY: Numbers are thin; they lack (in Mark Johnston's phrase) a "hidden substantial nature." There is no more to them than the concept of a number demands. Even if we are not able to work out all that that entails, we do know some of the features that are not entailed, and the suggestion that these nevertheless apply strikes us as comical. All of this is what you would expect of something conjured up for representational purposes. Why should we have filled out the story further than needed?

INDETERMINACY: Numbers' identity-relations are strikingly less determinate than those of regular objects. There are lots of things $\mathrm{X}$ such that there fails to be a fact of the matter as to whether $7=\mathrm{X}$. . This is only natural if 7 is made up. (There is no fact of the matter either as to whether my keister $=$ my wazoo, or the chip on my shoulder today $=$ the one that was there yesterday.)

TRANSLUCENCY: You "see through" my statement that the number of zebra mussels has doubled in a year to the fact I was trying to get across: there are twice as many zebra mussels as a year ago. You do not even register the as-if reference to numbers, and you are surprised when it is pointed out. This makes sense if numbers are representational aids rather (or more) than things-represented. (You "see through" my statement that Gandhi had a lot of guts in the same way.)

IMPATIENCE: People making statements purporting to be about numbers are strangely indifferent to the question of their existence. Suppose that you as a math teacher tell little Fred that what 2 and 3 add up to is 5 . And suppose some meddler points out that according to the Oracle (which let us assume we all trust), everything is concrete and so not a number. Instead of calling Fred in to confess your mistake, you tell the meddler to bug off. This makes sense if the meddler's information is irrelevant to what you were really saying -- as indeed it is if your message was that it is five things (not six as Fred had supposed) that two 
things and three other things amount to. (Compare being rebuked for saying that Gandhi had a mind of his own on the basis that Gandhi was wholly physical.)

REPRESENTATIONALITY: All abstract objects yet discovered have "turned out" to come in handy as representational aids. How is this interesting coincidence to be explained? Why have numbers, sets, properties, and so on all turned out to be liable to the same sort of use? This should remind us (says the figuralist) of Wittgenstein's fable in which we first invent clocks, and only later realize that they could be used to tell time. It is no big surprise if things with representing as their reason for "being" show a consistent aptitude for the task.

NECESSITY \& APRIORITY: That a thing should exist is the paradigm of a contingent, aposteriori, state of affairs. Yet arithmetic, which is up to its neck in existential commitments, strikes us as apriori and necessary. Why? Suppose as suggested above that the real content of " $2+3=5$ " is $\left(\exists_{2} \underline{\underline{x}} F \underline{\mathrm{x}} \& \exists_{3} \underline{\underline{y}} \mathrm{~Gy} \& \sim \neg \underline{\underline{z}}(\mathrm{~F} \underline{z} \& \mathrm{Gz})\right) \rightarrow \exists_{5} \underline{\underline{u}}(\mathrm{Fu} \vee \mathrm{G} \underline{u})$. This is a logical truth, and to that extent necessary and apriori. Arithmetic seems necessary and priori because at the level of real content, it is. ${ }^{13}$

\section{What explanatory puzzles does figuralism generate?}

If we are just pretending to assert, when we say that the number of planets is 9 , shouldn't we know it? How does the figuralist propose to explain our obliviousness on this score?

One form of the objection has already been discussed: we are not just pretending to assert, when we say the number of planets is 9 . We are really asserting that there are nine planets. But the claim will be that we are not pretending at all: not even instrumentally as a way of asserting something believed.

If pretending is making believe, where "making" signifies an act deliberately undertaken, then the objection seems right. Nothing like that happens when we exchange notes on the number of planets.

But does the figuralist need it to happen? Making believe is an amalgam of (i) being as if you believe, and (ii) being that way through your deliberate efforts. It is only (i) that the figuralist needs. Call it simulation. ${ }^{14}$ Someone is simulating belief that $\mathrm{S}$ if although 
things are in relevant respects as if they believed that $S$, when they reflect on the matter they find that they do not believe it; or at least are agnostic on the matter; or at least do feel the propriety of their stance to depend on their belief that $S$ if they have one. They do not believe that $\mathrm{S}$ except possibly per accidens.

Simulating is being in relevant respects as if one believed, while not believing except possibly per accidens. Copernicus after realizing the astronomical facts still simulates belief in a setting sun. Einstein having developed relativity theory still simulates belief in absolute rest and motion. A movie-goer who realizes full well she is looking at moving images may still simulate the belief that she is being attacked by a giant squid. A dreamer may simulate the belief that she is winning the Nobel Prize. ${ }^{15}$

Making believe is a conscious activity, or one easily brought to consciousness. Simulating is not. It may even come as a great surprise that one is simulating. It came as a great surprise to me to realize that although it was as if I believed that an invalid argument was one with countermodels, I did not really believe it save per accidens -- for I did not believe in models save per accidens.

Someone who utters a sentence committed to X's is to that extent simulating belief that X's exist; for uttering that sentence is a way (not always a deep or thoroughgoing way) of bringing oneself into a relation of resemblance with the (possibly hypothetical) person who believes the sentence's literal content.

\section{Summing Up}

The predicament we started with can be stated as follows: what are our options when we discover that we are (only) simulating a belief in X's? As before, one option is to stop simulating by ceasing to be as if a believer in X's. A second option is to stop simulating by becoming a genuine believer in X's. (Or, in light of the "except per accidens" clause, one should come to express genuine belief in uttering the sentence.) A third is to keep on simulating, but only when one is in possession of a paraphrase that one can really believe. (Or, in light of the "except per accidens" clause, really believe qua utterer of that sentence.)

What the fictionalist offers is a fourth option. Your simulated beliefs and assertions may be tracking a realm of genuine facts, or a realm of what you take to be facts. If so then 
it becomes tempting to construe the simulated assertion that $\mathrm{S}$ as a real assertion about the relevant facts -- the facts that make a simulation like that appropriate.

There is a danger, though, of that construal seeming contrived or self-serving. Am I engaged in legitimate self-analysis, or am I "tampering with the record" to bring past statements in line with current beliefs? This is where the specifically figuralist version of the doctrine comes in. One responds to the threat of self-servingness by pointing out how similar our talk of X's is to our (certifiably figurative) talk of Y's.

If Hattie says "the prof put a lot of hurdles in my path," it is not at all contrived to regard her as simulating to some small extent the belief that her professor (literally) put a lot of hurdles in her path. And it is not at all contrived to regard her as really expressing a belief to the effect that their professor made it in thus and such ways difficult for her to accomplish what she had wanted to. The challenge in any particular case is to make out that one's talk of X's resembles figurative speech enough to make this sort of construal ring true.

Deciding whether a construal "rings true" is a difficult task, not made easier by our tendency toward wishful thinking and the rewriting of history. It may be that figuralism is a tool inherently liable to a certain sort of misuse. One certainly hopes for more and better controls on the operation than I have been able to provide in this paper.

But a tool liable to misuse is not automatically worthless. It may even be indispensable for some purposes. Compare the notion of conversational implicature. Grice came to regret his invention to some extent; he was not sure he knew how to use it responsibly, that is, non-opportunistically. He never concluded, though, that one should scrap the idea. Implicature happens, so there is no real option but to try to develop a working relationship with it. Figuration happens, too. You learn by trying. ${ }^{16}$

\section{$\underline{\text { Appendix on Jason's Critique }}^{17}$}

"Hermeneutic Fictionalism" has a number of targets, not all of whom agree on everything. The following responds from my own not entirely stable perspective to some of the questions it raises. 
Section II of the paper lays out "several problematic consequences of any interesting application of hermeneutic fictionalism." Section III argues that extant HF (hermeneutic fictionalist) analyses are independently untenable. I will start with section III, since the part relevant to me centers around a single example: ${ }^{18}$

(3) The average mother has 2.3 children.

I have no great investment in the example -- Jason may well be right about it -- but it is worth discussing as it brings out some (to me) interesting methodological differences.

A fictionalist analysis of (3) would say that taken literally, it is committed to an average mother; it is not literally true unless such a thing exists. The objection to this has been changing and I am still not sure I have it right. Originally (at the APA session), the problem was said to be that 'the average F' is not a "normal definite description" like 'the red car'. This is shown by the fact that (7b) is less acceptable than (7a), but (9a) and (9b) are both OK.

(7a) The average red car gets 2.3 tickets per year

(7b) The red average car gets 2.3 tickets per year,

(9a) The shiny red car has a flat tire

(9b) The red shiny car has a flat tire

But the fictionalist never said that 'the average $\mathrm{F}$ ' was normal, and it seems clear that it isn't. 'The red car' is normal because it purports to pick out the car with the monadic property of being red. 'The average car' does not purport to pick out the car with the monadic property of being average. That would be silly. There is no more a property of being (simply) average than there is a property of being shortest or first.

Normality is a red herring; 'the average star' does not pretend to be normal. The contrast between (7) and (9) is the same herring again. It arises because 'the red car' is normal and 'the average car' is not. You get the same contrast if 'the average car' is replaced by 'the shortest spy.' Should we conclude that 'the shortest spy' does not purport 
to refer? Agreeing that we shouldn't, Jason tries to show that 'the average F' is in some other way special. He makes two proposals on this score. The first is that

(13) The shortest spy is in France, but there is no shortest spy

contradicts itself, while

(14) The average mother has 2.3 children, but there is no average mother

could be true. Now, of course, the fictionalist agrees that (14) could be true; (14) might indeed be read as a statement of fictionalist doctrine on the matter. If it were literal truth that (14) were capable of, the fictionalist would have some explaining to do. But according to him, (14)'s first conjunct is a candidate at best for figurative truth. The second conjunct is not a candidate for figurative truth, or even for figurative interpretation. It has to be taken literally, and so taken, it is true. To the extent (14) strikes us as true, this is because the first conjunct is true on its most natural interpretation, and the second conjunct is true on its.

A similar situation arises with Carnap's internal/external distinction. Carnap explains the distinction in two ways. On the one hand, we are given examples. An example of an external question is "Are there numbers?" An example of an internal question is "Are there numbers which added to 3 yield 5?" There is a principled explanation as well. Internal questions are "plain" and settled in agreed-on ways. External questions are "philosophical" and debated inconclusively for centuries.

There has always been a problem seeing how the two explanations are supposed to fit together. If internal $=$ plain and external $=$ philosophical, then what marks a question as one or the other is the spirit in which it is posed. There is nothing to prevent us from asking in an internal vein whether there are numbers, or in an external vein whether there are numbers which added to 3 yield 5. But then what is going on in the first explanation? If the distinction is not about words but spirit, how is it that one sequence of words puts us immediately on an internal track, while another is hard to hear as anything but external? 
A fictionalist could explain it as follows. "There is a number that added to 3 yields 5" has a real content and a literal content. The first is a long disjunction: no things and three things make five things, or one thing and three things make five things, or two things and three things make five things, or etc. The disjunction raises no deep metaphysical issues and can be confirmed in agreed-on on ways. Questions about the real content are to that extent internal questions.

If Hattie asks whether there is a number that added to 3 yields 5 , she is probably asking about the real content. Concern about the literal content over and above the real is concern about the metaphysics of numbers. If Hattie is concerned about the metaphysics of numbers, she has chosen a funny way to express it. Why inquire about these numbers rather than those, when the whole lot stand or fall together? "Is there a number that added to 3 yields 5 ?" thus lends itself to the expression of internal curiosity.

What about "are there numbers"? If Harry asks about that, is he asking about real content? Not likely, for the sentence has no real content to speak of. The literal content is the only game in town, and so one has to assume that it is the literal content Harry is asking about. There are no agreed-on ways of evaluating this content. Harry is therefore asking an external question.

Suppose that Harry is a nominalist who works as a mathematician. He accepts "there is a number which added to 3 yields 5 " because he takes it non-literally, and so taken it is true. He rejects "there are numbers" because it can only be taken literally, and so taken it is false. That is not unlike our own situation with respect to the average mother. "The average mother has 2.3 children" sounds right, because we do not take it literally, and its real content is true. "There is an average mother" sounds wrong, because we do take it literally, and its literal content is false. This explains both why (14) is jarring, and why it nevertheless strikes us as correct. ${ }^{19}$

Jason has a second argument for exceptionalism about "the average mother." "Suppose that the semantic function of "the average mother"...were to pick out a unique entity. Then, (15a) and (15b) would follow trivially from the premise that mothers have mass: 
(15a) If there are any mothers at all, then there is some mother who is an average mother in terms of weight.

(15b) If there are any mothers at all, then there is a mother of average weight.

But the sentences in (15)....unambiguously express substantive truths."

Why does Jason assume that (15a) and (15b) would follow trivially? Perhaps he is thinking that someone who as-if believes in an average mother must also as-if believe that she is one of the mothers. That cannot be how the fiction works. If average F's were to be thought of as F's, we would run into impredicativity problems. The average mother's properties would depend on the properties of the average working mother, which would depend conversely on the properties of the average mother, who for all I know works. Also, the average mother's properties would depend on those of the average single mother, the average stay-at-home mother, and so on without limit. Average mothers should not be mothers, and they do not have to be mothers, not any more than former Presidents and toy trucks have to be Presidents and trucks.

Now let me turn from Jason's discussion of "best cases" for fictionalism to the problems he raises for any application of the strategy. I agree with a great deal of what he says. My worries are more about things that he doesn't say, but that must be assumed if we are to reach the conclusion that "hermeneutic fictionalism is not a viable strategy in ontology."

\section{Systematicity}

Clearly, "speakers have an extraordinary ability to understand the real world truth-conditions of sentences." Allowing for possible differences about the meaning of "systematic," we can agree too that the most natural explanation of this ability postulates "a systematic relationship between the real world semantic values of the parts of the sentences, and the real world semantic values of the whole sentences." The more a semantic theory departs from systematicity, the harder it becomes to explain why understanding is not thereby rendered mysterious.

But, HF is not a semantic theory in the sense apparently intended: the sense in which Davidson advocates one kind of semantic theory and Montague another. HF is a 
strategy aimed at particular constructions. There is or need be no general program of understanding things in HF terms. If one HF analysis fails, another might succeed. An objection on the score of systematicity must therefore maintain something very strong: take whatever construction you like, HF analyses of that construction are bound to be so unsystematic as to leave our understanding a mystery.

At one point, Jason suggests he is only echoing Walton's pessimism. I wonder if they are pessimistic about the same thing. When Walton says that there is no "simple and systematic way of understanding how fictional truths are generated" $(1990,139)$, he is saying that there is no simple recipe for fictional truth in general. He thinks there is no general meta-rule that tells you how to find object-rules (rules of generation) in all the contexts in which they might be thought to arise. Walton is not saying that this or that individual rule of generation is unsystematic. Nothing can be said at that level of generality. Rules of generation aren't all the same.

I have a worry from the other direction as well. There are various things that might be meant by "systematicity." At one end we have weak systematicity; it's enough for this if there is a possible human-like machine that non-miraculously delivers the right results. At the other end is strong systematicity: the right results should be obtainable by recursive compositional rules.

Jason is right that HF semantics is not often strongly systematic. That is a problem, if we are dealing with abilities that one would expect to be strongly systematic if systematic at all. Are we?

There are kinds of speech that finite beings clearly do understand, yet whose semantics does not seem to be compositional. One does not expect a compositional semantics for hyperbole, metonymy, or irony; one does not expect a compositional semantics for speech governed by shifting presupposition. Somehow, though, we understand. This suggests that HF-style analyses directed at kinds of speech that resemble hyperbole, metonymy, or etc. should not be held to the standard of strongsystematicity-or-bust.

Consider again applied arithmetic. Someone speaking hyperbolically is inviting us to chip a stronger literal content down to a weaker real content. This happens with applied arithmetic, too. What is the literal content of "the number of sheep is three times 
the number of goats"? Roughly this: The sheep have associated with them a number that stands to the number associated with the goats in a certain numerical relation, a relation that the number of F's bears to the number of G's only if there are three times as many $F$ as G's. The real content is that there are three times as many sheep as goats. It does not seem very mysterious how we get from the one to the other. The real content is that portion of the literal content that concerns the sheep and the goats.

The interpretation rule here can be formulated in more than way. David Lewis suggested the following. Let propositions be sets of worlds. A proposition $\mathrm{P}$ is entirely about subject matter $\mathrm{M}$ iff $\mathrm{M}$-equivalent worlds always agree on $\mathrm{P}$. It is partly about $\mathrm{M}$ iff some weaker $\mathrm{P}^{-}$is entirely about M. (This much is from Lewis 1988.) A sentence whose literal content $\mathrm{P}$ is partly about the physical world has its real content the strongest $\mathrm{P}^{-}$that is entirely about the physical world. Gideon Rosen has another way of stating the rule, and Mark Balaguer another yet. The point is that stronger literal contents are mapped to weaker real ones according to an explicit rule. This is very like hyperbole with an explicit chip-down rule. If hyperbole with an explicit chip-down rule is OK, then so is what the fictionalist is proposing.

Another useful comparison is with "tactical presupposition" as envisaged by Robert Stalnaker. Suppose that C is the set of worlds in play at a particular point in our conversation (the context set). The contribution you want to make would restrict attention to a certain subset D of C. But you are unable to make it, for lack of an appropriate sentence. If you could shrink the context set momentarily to $\mathrm{C}^{\prime}$, you could use sentence $\mathrm{S}$ to mark out the corresponding subset D' of C'. D would then be recoverable as the most natural extension of D' to the original context set C. Example: Suppose for a second -you need not believe it -- that there is a man in the moon. Then the place I am saying the spaceship landed is right by the left eyebrow. Example: Suppose for a second -- you need not believe it -- that if there are two F's then the F's have associated with them an entity 2 that is their number (and similarly for three F's, four, etc). Then the reason I am saying we cannot tile the floor with these is that their number is prime. ${ }^{20}$

\section{Inaccessibility}


According to HF, "whether or not someone is engaged in a pretense is inaccessible to that person.... $[\mathrm{HF}]$ introduces a novel and quite drastic form of failure of first-person authority over one's own mental states."

This would be a problem, if the hermeneutic fictionalist's attitude of choice was pretense in the ordinary sense of the term. Everyone who writes on the topic, however, makes an effort to distance themselves from such a notion. Walton in Mimesis and Make Believe counts dreams as a kind of pretense. Assumptions hard-wired into cognitive mechanisms count too:

There is (I assume) no such thing as absolute motion and rest....Our perceptual experiences seem not to accord with these facts, however. What we see as fixed can change. When my train pulls out of the station I may at first see it (and myself) as stationary and a train on the next track as in motion; I may then switch to seeing the other train as fixed and mine as moving. Neither perspective is correct; neither train is in motion simpliciter, or stationary simpliciter....

It is not impossible to describe events without relying on this fiction....But descriptions of relative motion are awkward...it is usually easier and more perspicuous to speak and think as though....some things are really stationary and others are really in motion.

Perceiving in terms of the fiction seems not to be optional, even if speaking and thinking in terms of it is. Try as I might, I cannot perceive things as I think they really are; I cannot see two objects as moving relative to one another without seeing one of them, or a third thing, as fixed absolutely. ... The make-believe seems to be indispensable as far as perception is concerned... (Walton 2000, 789)

Walton says that perception of motion involves a make believe, that we perceive in terms of the fiction, and so on. It is clear that dreamers do not in any ordinary sense pretend 
that they are flying, nor do perceivers pretend that motion and rest are absolute. It must be that Walton is using the word in an extended sense.

I do not say it is clear what that sense is. A number of philosophers have tried to develop a notion of acceptance falling short of belief (van Fraassen 1980, Bratman 1992, Cohen 1992, Velleman 2000). One approach emphasizes constitutive aims. Belief aims at truth; if it lands on a falsehood, then something has gone wrong. Acceptance is not so demanding. It is satisfied if a sentence counts as true, or can be treated as true, or is true enough for present purposes.

Another approach starts from belief and work backwards. To accept that $\mathrm{S}$ is to resemble in such and such cognitive respects someone who believes that S. Mere acceptance is resembling a believer without being one.

Acceptance is conceived as here and now; belief, or what belief adds to acceptance, lies partly elsewhere. Belief has dispositional and future-looking aspects (continued acceptance on reflection, willingness to use $\mathrm{S}$ as a premise even when context is unclear) that acceptance lacks.

Someone might say that acceptance is more properly called shallow belief, and its dispositional counterpart deep belief, or conviction, or some such thing. The issue is complicated by the fact that accepting $S$ may go with believing $S^{*}$, where a belief that $S^{*}$ would standardly be reported as a belief that S. ("Yablo believes that the number of Chinese will soon be exceeded by the number of Indians" is in almost all contexts true, since Yablo does believe what the embedded sentence really says.) Let me not get into that issue here. It is enough to note that the attitude that HF denies us immediate authority about is the dispositional and forward looking attitude. There is no presumption of authority about attitudes like that. If anything the presumptions run the other way. One does not expect people to know what they would say or do in counterfactual circumstances, especially when the circumstances include some they can form no clear conception of.

\section{Psychology}

"The most straightforward way to understand the hermeneutic fictionalist's [claim that] engaging in games of make-believe is like engaging in the ontologically 
controversial discourse is that the very same psychological capacity is involved in both activities....[I]n any non-explicitly fictional discourse of interest to metaphysicians, [that] thesis ...is likely to be subject to empirical refutation."

HF is in the first instance a semantical hypothesis. It says, here is what the real truth conditions are, and here is what determines them. The semantic hypothesis might be taken to argue for a story about psychological processing, or vice versa. And psychological claims might also be made of a more motivational nature. But an HF hypothesis narrowly drawn is about some particular bit of language: what it means, and how the meaning is determined. It does not directly matter then if the psychology of arithmetic is different from the psychology of make believe. (Not that a connection couldn't be made.)

If the above holds for HF advocates generally, the figural fictionalist will be particularly suspicious of claims about special processing. Once it was thought that interpreting figurative speech was a two-stage process: first you try for a literal interpretation, then, failing to find one, you look elsewhere. This is an empirical claim and one that appears to have been refuted (Gibbs, Chapter 3).

\section{Motivation: Desire to Avoid Commitment}

According to HF, "speakers are simply pretending that the objects ... exist, in order to express something ontologically innocent." But this motivation is not generally compelling. "Someone who is unfamiliar with Davidson's account of adverbs might very well deny that by believing what is expressed by "John is walking slowly," she is thereby committed to the existence of events. But it is not at all plausible to suppose that the reason she is not so committed is that she is only pretending there are events. After all, she has no clue that the best semantic theory in fact commits her to events."

I have already said that speakers need not be in the relevant sense "pretending." There may be no deliberate act: just a finding on reflection that the acceptance was not so wholehearted as to count as belief.

Related to this, the hermeneutic fictionalist does not see speakers as motivated by the desire to avoid commitment. Some hermeneutic fictionalists are not even themselves motivated by the desire to avoid commitment. Some of them just believe that the speech 
is not in fact committal, welcome or unwelcome as the suggestion may be found. One can believe in events without supposing that one is talking about them whenever using an adverb. (Compare Boolos: even a set theorist may find it helpful to realize that plural quantification is not singular quantification over sets.)

Anyway, it is not clear that "the best semantic theory" does commit the speaker to events, even if the best semantic theory is Davidson's. A distinction needs to be drawn between the speaker's commitments and those of the semantic theorist trying to understand her. Quine the semantic theorist thinks predicates stand for sets. He denies however that one incurs a commitment (to sets or anything else) just by using predicates. This seems only natural. If speakers were committing herself to sets, then it would be inconsistent or self-defeating to say "there are no sets." One would be disavowing a commitment that one was at the same time incurring. And clearly it is not inconsistent to say this. (It might be inconsistent to suppose that one does incur the commitment, for then one would be committed to a set of all sets.)

A philosopher who does think semantic theory is a way of doing ontology is Donald Davidson ("The Method of Truth in Metaphysics"). It is not worth noting, however, that Davidsonian semantics is done in a metalanguage not much stronger than the object language. Davidson never imagines for a moment that semantic theory done, say, Montague's way tells us what there is, or what the thinker is committed to. It is also worth pointing out that Davidson does not take the link with ontology be straightforward. He gives a sophisticated transcendental argument for it. One has to believe in the things needed for axiomatic truth theory, because axiomatic truth theory is needed for learnability, and a learnable language is the only kind for us. (Myself, I do not see how the fact that we could not understand if something in us was not quantifying over events is a reason to think that there really are such things.)

\section{Motivation: Flawed Semantic Analysis}

Particular fictionalist analyses "are often motivated by a flawed conception of what the best semantic theory for a particular stretch of discourse happens to be....For [the] argument to have force, it must be .... that the best semantics for, e.g., "the number of Democrats is on the rise" treats "the number of Democrats" as an expression that picks 
out a particular number. However, it is at best suspect that the correct semantic theory...functions in the manner [required]" (20).

This assumes what I have just denied, namely, that the speaker has her commitments decided by the semantic theorist. Say the theorist tells us that "the number of Democrats" stands for a function from times to numbers. (This is suggested by Jason in a footnote.) Is the speaker then committed to functions? If so, why is the speaker not being inconsistent when she adds "and the number of functions is, as ever, zero"?

A linguistic argument could perhaps convince us that "the number of Democrats" does not purport to refer. But if it does purport to refer, then surely it purports to refer to a number. This is on the principle that "the so and so....," taken literally, purports to refer to a so and so if to anything. It may be, of course, that "purports to refer" is not a

notion linguists have any use for. That is OK with me. It's one more reason not to think of what linguists do as the key to ontological commitment. I am not sure that linguists greatly disagree with this.

\section{Motivation: Actual versus Believed Commitments}

"It is unclear why [the notion of the commitments the speaker believes she has] should have any interest for the project of ontology. There are many commitments we have that we do not recognize we have. For example, many of us believe the axioms of Peano arithmetic. We are therefore committed to their consequences. However, there are many such consequences which we do not recognize that we are committed to...the study of arithmetical commitments speakers believe they have is surely not a very interesting topic."

"Commitments speakers do not recognize" has the same ambiguity as "things speakers do not believe." I am not claiming relevance for commitments speakers have not concluded they have. I am claiming relevance for commitments speakers have concluded they lack. The unrecognized arithmetical commitments that Jason is talking about are simply not known by the speaker to be commitments. One can agree that not much interest attaches to speakers' computational limitations, while still insisting that we take seriously the conclusions they are able to draw. (If Bloggs starts denying that he is committed to various classical theorems, this would be of semantic interest..) 
"Perhaps ontology should be in the business of uncovering the actual ontological commitments we incur when we use a discourse, rather than the ontological commitments speakers believe they incur."

Perhaps, but I am still looking for the motivation. Philosophers are interested in which combinations of attitudes are open to criticism as inconsistent. I had thought this was the reason for being interested in ontological commitments. The point of "in saying $\mathrm{S}$ one is committed to $\mathrm{F}^{\prime} \mathrm{s}$ " is that it tells us that if $\mathrm{S}$ is what we think, we cannot consistently deny that there are F's. That is certainly one notion of commitment. If it is a mistake to be interested in it, one would like to hear the reasons.

If commitment is linked in this way to consistency, what would be the point of distinguishing actual commitments from believed commitments? Perhaps the thought is that people are not good judges of when they are or would be consistent in maintaining both that $\mathrm{S}$ and that BLAHs do not exist." Speakers' judgments about when they are contradicting themselves are therefore to be swept aside in favor of a superior sort of intelligence on this topic available from source X. I do not know that I have any real objection to this; it could be good. But what is source X?

\section{Motivation: Unequal Authority}

Hermeneutic fictionalists assume that "a speaker has first-person authority over the ontological commitments she incurs when using a discourse. However, to maintain this assumption, [they] must give up the thesis that we have first-person authority over whether or not we are pretending. But surely the thesis that we have first-person authority over our commitments is considerably less plausible than the thesis that we have first-person authority over whether or not we are pretending" (20-1).

This makes it sound as though the fictionalist grants us an authority here that he denies us there. But the authorities involved are quite different. The authority-granting thesis is this: deference is owed to those who persist in thinking they are not contradicting themselves, no matter how many times the supposed contradiction is pointed out. Jason suggests that fictionalists change their tune when it comes to pretense vs. belief; they maintain that deference is not owed to speakers who persist in thinking that they really 
believe something. But that is not true. Deference begins to be owed about belief vs. pretense at around the same time as it begins to be owed about commitments.

Suppose that Hattie decides she does not incur a commitment to superegos when she says "Nixon had a stunted superego." She decides that she would not consider herself to have been refuted if there turned out not to be any such things. Now she can engage in the following reasoning: (a) the sentence taken literally presupposes superegos, (b) the sentence taken the way I meant it does not presuppose superegos, therefore (c) I did not mean it literally. She might, of course, be slowed down by (a). But problems about (a) are not problems of first-person authority or self-knowledge.

\section{Bibliography}

Alston, W. 1958. "Ontological commitment," Philosophical Studies 9, pp. 8-17

Balaguer, M. 1996. "A Fictionalist Account of the Indispensable Applications of Mathematics," Philosophical Studies 83, pp. 291-314

Balaguer, M. 1998. Platonism and Anti-Platonism in Mathematics (New York: Oxford University Press)

Bratman, M. 1992. "Practical Reasoning and Acceptance in a Context," Mind 101, pp. 1-15

Burgess, J. \& G. Rosen, 1997. A Subject With No Object (Oxford: Clarendon Press)

Carnap, R. 1956. "Empiricism, Semantics, \& Ontology," in his Meaning \& Necessity, 2nd edition (Chicago: University of Chicago Press)

Cohen, J. 1992. An Essay on Belief and Acceptance (Oxford: Clarendon)

Crimmins, M. 1998. "Hesperus and Phosphorus: Sense, Reference, and Pretence" Philosophical Review 107, pp. 1-47

Davidson, D. 1977. "The Method of Truth in Metaphysics," Midwest Studies in Philosophy 2, pp. 244-254 
Davidson, D. 1978. "What metaphors mean," in Sacks 1979

Davies, M. 1983. "Idiom and Metaphor," Proceedings of the Aristotelian Society 83, pp. 67-86.

Davies, M. and T. Stone, 1995. Mental Simulation (Oxford: Blackwell)

Derrida, J. 1982. "White Mythology: Metaphor in the Text of Philosophy," in Margins of Philosophy (Chicago: University of Chicago Press)

Field, H. 1989. Realism, Mathematics, \& Modality (Oxford: Blackwell)

Field, H. 1980. Science Without Numbers (Princeton: Princeton University Press)

Fodor, J. and J. Katz, 1963 "The Availability of What We Say," Philosophical Review 72, pp. 5771

Fodor, J. 1964. "On Knowing What We Would Say," Philosophical Review 73, pp. 198-212

Gibbs, R.W. 1994. The Poetics of Mind: Figurative Thought, Language, and Understanding (New York: Cambridge University Press)

Hills, D. 1998. "Aptness and Truth in Metaphorical Utterance," Philosophical Topics 25, pp. 117153

Katz, A., C. Cacciari, R. Gibbs, and M. Turner, Figurative Language and Thought (New York: Oxford University Press)

Maddy, P. 1997. Naturalism in Mathematics (Oxford: Clarendon)

Melia, J. 1995. "On what there's not," Analysis 55, pp. 223-229

Lakoff, G. and R. E. Nuñez, Where Mathematics Comes From (New York: Basic Books)

Lewis, D. K. 1988. "Statements Partly About Observation," Philosophical Papers 17, pp. 1-31

Nolan, D. and J. O'Leary-Hawthorne. 1996. "Reflexive Fictionalisms," Analysis 56, pp.23-32.

Ortony, A. 1993. Metaphor and Thought, 2nd edition (Cambridge: Cambridge University Press)

Quine, W.V. 1948. "On what there is," Review of Metaphysics 2, reprinted in Quine 1953

Quine, W.V. 1953. From a Logical Point of View (Cambridge, MA: Harvard University Press)

Quine, W.V. 1960. Word \& Object (Cambridge: MIT Press)

Quine, W.V. 1978. "A Postscript on Metaphor," in Sacks 1978

Rosen, G. 1990. "Modal Fictionalism," Mind 99, pp. 327-354

Rosen, G. 1993. "A Problem for Fictionalism About Possible Worlds," Analysis 53, pp. 71-81

Sacks, S., ed. 1978. On Metaphor (Chicago: University of Chicago Press)

van Fraassen, B. 1980. The Scientific Image (Oxford: Oxford University Press) 
Velleman, D. 2000. "On the Aim of Belief," in his The Possibility of Practical Reason (Oxford: Clarendon)

Walton, K. 1990. Mimesis \& Make-Believe (Cambridge, MA: Harvard University Press)

Walton, K. 1993. "Metaphor and Prop Oriented Make-Believe," European Journal of Philosophy 1, pp. 39-57

Walton, K. 1997. "Spelunking, Simulation, and Slime," in M. Hjort \& S. Laver, ed. Emotion and the Arts (Oxford: Oxford University Press)

Walton, K. 2000. "Existence as Metaphor," in A. Everett \& T. Hofweber, ed. Empty Names, Fiction, and the Puzzles of Existence (Stanford: CSLI)

Wright, C. 1983. Frege's Conception of Numbers as Objects (Aberdeen: Aberdeen University Press)

Yablo, S. 1996. "How in the World?," Philosophical Topics 24, pp. 255-286

Yablo, S. 1998. "Does Ontology Rest on a Mistake?," Proceedings of the Aristotelian Society, supp. vol. 72, pp. 229-262

Yablo, S. 2000. "Apriority and Existence," P. Boghossian \& C. Peacocke, ed., New Essays on the A Priori (Oxford: Oxford University Press)

Yablo, S. forthcoming. "Abstract Objects: A Case Study," in Philosophical Issues

Yablo, S. manuscript. "The Myth of the Seven"

\footnotetext{
${ }^{1}$ Better, we don't think the propriety of our stance depends on the belief, even if we have it. You may have horses for all I know. But I am not committing myself on the topic when I say you should hold your horses.

${ }^{2}$ Quine 1960, 210.

${ }^{3}$ Quine 1960, 210.

${ }^{4}$ Quine 1961, 103.

${ }^{5}$ Quine 1960, 219.

${ }^{6}$ Full quotation: "we feign belief in the antecedent and see how convincing we then find the consequent" (Quine 1960, 222).

${ }^{7}$ Quine 1960, 248ff.

${ }^{8}$ There will, of course, be more to the fictions than is indicated here.

${ }^{9}$ Field has a good discussion in his 1980.

${ }^{10}$ Nolan and O'Leary-Hawthorne 1996.

${ }^{11}$ I am relying here on a perhaps-too-subtle distinction between (i) saying $\mathrm{S}$ meaning: in the game, $S$, and (ii) saying it meaning: $\underline{S}$ (pssst -- judge this by its faithfulness to reality as we are supposed to imagine it when doing arithmetic)." (i) makes life simpler. Our subject matter is always the same: the world as it is. But (ii) better captures how it feels
} 
to say that there are infinitely many primes. I feel myself to be talking not about the practice, but the objects. (Why otherwise is the infinity of the primes necessary and apriori?) (Thanks to Mark Crimmins for pressing me on this.)

${ }^{12}$ Burgess \& Rosen 1997.

${ }^{13}$ See "Abstract Objects: A Case Study."

${ }^{14}$ I take the term, or anyway this way of using it, from Walton, "Spelunking, Simulation, and Slime."

${ }^{15}$ The examples are from Walton; he provides much interesting detail, especially about absolute rest.

${ }^{16}$ This paper was written for an APA Symposium on Semantic Pretense organized by Mark Richard. Mark Crimmins spoke as well, and the commentators were Thomas Hofweber and Jason Stanley. Thanks, you guys. And thanks to the following for criticism and advice: Gideon Rosen, David Hills, Ken Walton, Bob Stalnaker, Penelope Maddy, Terry Horgan, Tamar Gendler, Peter Ludlow, and Ruth Millikan.

${ }^{17}$ This appendix started out as some footnotes about a paper that started out as an APA commentary on the present paper. The footnotes became a humongous endnote which at the editor's suggestion became what you see now.

${ }^{18}$ Unless the part about idioms was directed at me. I do not know why Jason thinks HF's see idioms as a best case. It might be because I have given long sloppy lists of "metaphors" that unbeknownst to me included some idioms. The intent has always been metaphorical. (See Davies 1983 for ideas about the distinction.)

19 If neither conjunct demands to be taken literally, unequal treatment becomes harder to defend, and (14)'s inconsistency becomes more apparent. One can imagine using "there is an average $\mathrm{F}^{\prime}$ to mean that F's are the sort of thing whose properties can sensibly be averaged. Talking like this, we might say that there is an average mother, but there is no average natural number. (14) now says that mothers have on average 2.3 children, although mothers are not of a type to be on average anything. That does sound inconsistent. Why, if "the average mother" does not purport to refer? (Russell attributes to Santayana the view that there is no God, and Mary is His mother." Our problem as interpreters is to find a basis for the unequal treatment that charity would seem to require.)

${ }^{20}$ I suspect that part of what bothers Jason is the sloppiness of (not fictionalist semantics but) fictionalist semanticists. Mea maxima culpa. 